\title{
Correction to: Patterns of glioblastoma treatment and survival over a 16-years period: pooled data from the German Cancer Registries
}

\author{
Ljupcho Efremov ${ }^{1,2}$ - Semaw Ferede Abera ${ }^{2} \cdot$ Ahmed Bedir $^{2} \cdot$ Dirk Vordermark $^{2} \cdot$ Daniel Medenwald $^{1,2}$
}

Published online: 13 April 2021

๑) Springer-Verlag GmbH Germany, part of Springer Nature 2021

\section{Correction to: \\ Journal of Cancer Research and Clinical Oncology \\ https://doi.org/10.1007/s00432-021-03596-5}

In the original article published, the name of the second author is incorrect. The correct name is Semaw Ferede Abera.

The original article has been corrected.

Publisher's Note Springer Nature remains neutral with regard to jurisdictional claims in published maps and institutional affiliations.

The original article can be found online at https://doi.org/10.1007/ s00432-021-03596-5.

Daniel Medenwald

Daniel.Medenwald@uk-halle.de

1 Institute for Medical Epidemiology, Biometrics and Informatics (IMEBI), Interdisciplinary Center for Health Sciences, Medical School of the Martin-Luther-University Halle-Wittenberg, Magdeburger Str. 8, 06112 Halle (Saale), Germany

2 Department of Radiation Oncology, Martin-Luther-University, Halle (Saale), Germany 